\title{
Content Analysis of Language Textbooks (English, Urdu, Sindhi) for
}

\section{Inclusivity}

\author{
Fozia Gulab * Ashar Johnson Khokhar ${ }^{\dagger}$
}

\begin{abstract}
Education plays an important role in preparing children to embrace diversity in the society with particular reference to accepting people with physical disabilities as equal contributors to the growth and development of the society and a textbook is an effective tool to achieve this objective (Kivirauma E Laitinen, 2014). The main purpose of this research is to study the representation of people with disabilities in the textbooks (text and illustrations) published by provincial and selected private publishers. This study uses content analysis method to analyze the content of the selected textbooks used at primary school level. Analysis of 58 textbooks (English, Urdu, Sindhi) indicates that people with disabilities are overlooked. Their representation in these textbooks is not only minimal but they are portrayed as being dependent and unproductive members of the society. This study highlights the importance of including texts about people with different disabilities and their achievements in school textbooks. The students, teachers, teacher educators and parents will understand better disability and how able-bodied and differently-able people share a lot together.
\end{abstract}

Keywords: Disability education, inclusiveness, textbooks.

\section{Introduction}

A large number of countries have made great progress in integrating physically and mentally disabled individuals into mainstream education systems and this has proved a catalyst in improving quality of life of individuals who are physically and intellectually disabled (IPID) as reported by United Nations in its reports (United Nations, 2013; Office of the High Commissioner for Human Rights, 2010). The first step towards the inclusion of IPID into the mainstream education system, and the social and cultural life of a society is finding out how many IPID there are so that this groups needs are also addressed in the national development and planning programmes. Pakistan has ignored this group and never had a serious exercise to count IPID. There are serious flaws in the data collected during the past national census. For example, the 1981 census find 30 households out of every 1000 with IPID (Population Census Organization, 1973, 1984). The previous census conducted in 1973 put this number at 115 (Population Census Organization, 1973) while the 1961 census says this number is 19 (Home Affairs Division, 1964). The contradictions are visible and one tends to mistrust the information given by the Government of Pakistan and its related bodies. The authentic studies by international donor organizations

\footnotetext{
*Notre Dame Institute of Education, Karachi. Email: fozia.gulab@ndie.edu.pk

${ }^{\dagger}$ Forman Christian College (A Chartered University) Email: asharkhokhar@fccollege.edu.pk
} 
put this number around 8 million people (Japan International Cooperation Agency, 2002; Waqar, 2014).

Pakistan became a signatory to the United Nations Convention on the Rights of Persons with Disabilities (UNCRPD) in 2008 and ratified it or it was ratified in 2011. This document binds the Government of Pakistan to improving access to all services for IPID so that they also become fully functional and productive citizens of Pakistan. The Government of Pakistan had many textbook improvement exercises since the signing and ratification of the UNCRPD. This study looks at how the language textbooks taught in primary schools in Pakistan (Urdu, English, and Sindhi) have been changing and how texts included in the language textbooks represent this large group of IPID. Whitbourne and Hulicka (1990) argue that textbooks are not only reflective of the Zeitgeist of a discipline but they also shape it. This study explores the assumptions about ability and disability in language textbooks, in the organization of the text and the language used in different texts. The researchers question what is assumed and presumed in the texts, in its organization and language and how that might influence and disturb the readers' singular able-only viewpoint (Atkinson, 1991).

The study further explores the representation of IPID in the selected textbooks positively i.e. depicting them as useful members of the society contributing to its progress and expansion or negatively i.e. portraying IPID as dependent citizens such as beggars.

This study is an endeavour to understand how the representation of disability in textbooks influences the understanding of IPID by individuals without physical and intellectual disabilities (IWoPID) The understanding of IPID by IWoPID is explored by studying the overall organization of textbooks and the details of language used in language textbooks and how this influences the understanding of IWoPID of IPID and what is taken for granted about IPID by IWoPID and IPID. This study is conducted with both theoretical and political objectives. The former focuses on adding to the knowledge to understand the 'Otherness' and the process of 'Othering' about IPID amongst IWoPID; while the latter is achieved by advancing the interests of the IPID by challenging the prevalent social and political power that IWoPID have over IPID. The researchers' interest in exploring the representation of IPID in language curriculum have guided them to ask the following questions:

1. What do students learn and know about disability and IPID from reading the content of the textbooks?

2. What do students learn about IPID in relation to their contribution to the development of the society?

3. How do the texts given in the language textbook represent IPID?

4. How do teachers and students interpret the information given in the text about IPID?

5. How do the texts read by students in the language textbooks reproduce or contradict negative cultural representations of disability?

6. Are the images of IPID in Pakistan reproduced or contradicted in the textbooks? 


\section{Literature Review}

The feminists theorists have suggested how the 'other' is constructed. Simone de Beauvoir explains the process of creating the 'other' and argued that the 'other' is constructed by portraying the other a weaker individual, for example, by portraying woman what man is not. A set of attributes, both the positive and the negative, is created, such as the first set as, rational/emotional; public/private; strong/weak; masculine/feminine; willful/submissive. The second set contains good, better, superior, rational, which is privileged, while the second set will reflect the difference between the privileged and the not-privileged such as, bad, inferior, and irrational. The superior meaning is assigned to 'self' and the negative, weaker and opposite meaning to 'other.' The idea of 'otherness' plays an important role in creating majority and minority identities. Identity creation is controlled by those who have greater political and social power in any society and culture. Sociologists have argued that identities are not innate but created as a process of social and cultural experiences of an individual and group (Zevallos, 2011).

The United Nations and various international organizations have been working to ensure 100\% inclusion of IPID in regular classrooms and many steps have been suggested and taken to provide such access to educational material and educational places. One area of focus was to bring IPID in regular textbooks by including success stories about IPID and their experiences within societal and educational settings. There is ample evidence proving the effectiveness of inclusive educational opportunities for IPID and IWoPID as suggested by Pijl and Frostad (2010) in their study. The effective opportunities created focussed on access and sensitization areas. The physical access to educational places is addressed through changes in the building structures while access to educational material is made possible by use of technology (Mrug \& Wallander, 2002). Despite all these steps, the evidence does not show considerable improvement in the social acceptance of IPID in society nor their full participation in educational settings and workplaces (Nilholm \& Alm, 2010). At school level teachers' attitudes towards IPID remains as a question mark and their apporoach in tackling the educational needs of those people seems to be nonprofessional (Avramidis \& Norwich, 2002). This might be due to the fact that teachers lack professional preparedness to work with IPID (European Agency for Development in Special Needs Education, 2010).

"Normality is a construct imposed on a reality where there is only difference" (Oliver, 1996) p. 88 and Linton (1998) suggested that the organizing principle of shared humanity binds both ability and disability. The researchers (Linton, 1998; Wendell, 1997; Douard, 1995) have argued that disability is actually idealization of normalcy. The able-only experiences are made part of the textbook and the ideas that are part of the text ultimately become the accepted universally normal or the new normalcy about disability and IPID. The individuals, groups and organizations working with and for the rights of IPID have challenged the notion of disability put forward by IWoPID as they argue that the position taken by IWoPID about IPID should be no different from the position taken by, for example, whites about non-whites. The cultural interpretations of disability found in the text contribute in forming consciousness and sensitivity toward disability and IPID. The texts may also help in increased understanding of disability and IPID and make IWoPID 
aware of their assumptions about IPID and bring both IWoPID and IPID within the universal framework of being human (Berube, 1997; Bérubé, 1996; Thomson, 2017, 1997). The texts also encourage and promote cultural stereotypes including disability stereotypes. The disability activists have highlighted such instances of stereotyping and worked towards removing these stereotypes from the textbooks (Campbell \& Schram, 1995; Jensen \& Burgess, 1997). The researches have suggested that such constructions lead to the development of negative attitudes towards IPID as through their insensitive representations of IPID they legitimize the constructed social realities within and through the textbook (Taxel, 1989; Alvermann \& Commeyras, 1994; Commeyras \& Alvermann, 1996).

The Centre for Studies on Inclusive Education, a UK-base rights charity, defined inclusive education as "founded upon a moral position which values and respects every individual and which welcomes diversity as a rich learning resource" (CSIE, 2015). The idea of inclusion incorporated in this understanding of inclusive education is to tackle prejudice by 'Restructuring cultures, policies, and practices to respond to diversity in ways that value everyone equally' (CSIE, 2015). This also included schooling beyond the walls and gates of school. The governments across the world have used textbooks to reproduce the culture they wanted to promote and discourage behaviour they describe as against the culture (Kivirauma \& Laitinen, 2014). Textbook is still used as a tool to reproduce cultural behaviours of the majority group and suppress the culture of the minority groups as this become evident from Carspecken and Apple (1992) work. They have argued in their research that textbook is a cultural product and carries and communicates explicit and implicit, intentional and unintentional meaning to learners (Carspecken \& Apple, 1992). The textbooks have made IPID invisible as they are not represented in the texts (Linton, 1998). A large survey conducted in 1994 (Hogben \& Waterman, 1997) found that teachers at all levels believed that textbooks are critical to learners' success. Textbook writers need to be aware of the difference between handicap and impairment. Oliver (1996) and Bickenbach (1994) explained the difference between these terms. For them, handicap is an environmental barrier that limits or bars the participation of IPID in various social, cultural and other aspects of everyday life while impairment is a specific condition such as physical, sensory and cognitive biomedical characteristics.

Cheng and Beigi (2011) quoted a Chinese saying: "children who learn together, learn to live together" (p. 240) and this is true in any classroom. English has gained a status that cannot be given to any other regional languages spoken in Pakistan, including the national language of Pakistan, Urdu, claimed (Zaidi \& Zaki, 2017). They also argued that governments, provincial and federal, are aware of students' struggle to learn English but they will continue enforcing their policy of teaching English to students from early classes. This has presented an opportunity to Textbook writers in Pakistan to present success stories of IPID from Pakistan and from other countries to make IWoPID aware of the achievement of IPID. These stories and discussion about these storied in the classroom will make students know more about IPID and their achievements locally and internationally and shed their biases tied to their traditional concept of what IPID can and cannot do.

English language is a core subject to be studied by all students till higher secondary school leaving certificate. The textbook communicates a 'cultural stew of images and 
stereotypes about disability that inevitably simmers on the back burner of everyone's consciousness' (P. M. Ferguson, Ferguson, \& Taylor, 1992). The images are either cultural, stereotyping and negative and thus ignore the experience of disability and IPID by presenting negative depiction. Corbett (1996) found that disability is equated with adversity, misery, suffering and weakness and a tragic news. This view shaped the textbooks and remained unquestioned for a long period. The views about disability and IPID are changing in the developed world as schools and textbooks are becoming inclusive and IWoPID are learning to live, study, travel and work with IPID. This perception has not changed much in Pakistan and many other third world countries. The researchers studying narratives found three categories around which narratives could be clustered. These categories are (1) the actors, (2) the setting, and (3) plot. The studies conducted in the UK still find stereotypical reference to disability though its frequency has reduced significantly (Hodkinson, 2016; Dyches, Prater, \& Leininger, 2009). A study of English textbooks in Iran found IPID invisible as they could not be found either in the images and in the text and they remained a marginalized group along with many other minority groups in Iranian society (Hodkinson, Ghajarieh, \& Salami, 2016).

Allport's contact theory and Zajonc's mere exposure theory suggest that bringing IPID and IWoPID in one classroom, creating an environment where both groups can learn together will develop positive attitudes towards IPID amongst able-bodied students as there will be more opportunities for interactions amongst students (Slininger, Sherrill, \& Jankowski, 2000). The researches have shown that an inclusive school environment and culture could not change students' attitudes towards IPID to a great extent as it neither resulted in spontaneous interactions (Diamond \& Tu, 2009), nor did it develop positive attitudes towards IPID in able-bodied students (Rillotta \& Nettelbeck, 2007). The researches (Favazza, Phillipsen, \& Kumar, 2000; Frea, Craig-Unkefer, Odom, \& Johnson, 1999) have shown that interventions by teachers and school administration were needed as IWoPID showed low level of social acceptance of IPID and negative acceptance and negative attitudes towards them. The negative behaviour is considered one of the major constraints of IPID becoming part of the whole school culture (World Health Organization \& World Bank, 2011; McDougall, DeWit, King, \& Miller, 2004). These attitudes were shown in the form of avoidance of social interaction, bullying and teasing behaviours (Llewellyn, 2000) and affected the academic performance of IPID (Cook, 2002) and their association with the school, their peers and teachers, leading them to withdraw from socializing with their peers and teachers (Hogan, McLellan, \& Bauman, 2000).

The low self-esteem and withdrawal from socialization also results from negative comments by IWoPID about IPID and the behaviors these inappropriate comments endorsed (Hogan et al., 2000). Scholars have suggested the need to go beyond the contact theory and exposure theory and to ensure full participation of IPID is looked at in the complete learning experiences designed and supervised by teachers across the whole school curriculum. The IWoPID should learn about IPID and taught the importance of valuing all students. The need idea to focus on the whole curriculum and the teaching and learning experiences of students is also supported by many studies (Yu, Ostrosky, \& Fowler, 2012; Ison et al., 2010). They argued that the general curriculum should embrace a disability awareness programme as it will encourage IWoPID to become aware of the presence 
of IPID amongst them and reduce barriers to the inclusion of IPID in the general school programme.

\section{Methodology}

This study uses the content analysis method. It is, as suggested by Neuendorf (2002) was a widely used method in humanities, arts and social sciences (communication, journalism, sociology, psychology, business etc) but now educational researchers are also using this method especially after the curriculum and textbook became an important area of research. Weber (1990) says that "content analysis is a research method that uses a set of procedures to make valid inferences from text" (p. 117). Cohen, Manion, and Morrison (2007) explain content analysis in both broader and narrower contexts. The broader context is a "process of summarizing and interpreting written data" (Sándorová, 2014) p. 96. The narrower context entails "a strict and systematic set of procedures for rigorous analysis, examination, and verification of the contents of written data" (Cohen et al., 2007) p. 475. Weber (1990) argues that content analysis shortens the long text into fewer words or short expressions. Content analysis as research methodology has both quantitative and qualitative aspects. The quantitative content, explains Dornyei (2007) as "manifest level analysis" (p. 246) that covers the descriptive and objective overview of the "surface meaning of the data" (p. 246) while qualitative content analysis is latent level analysis, a second-level, interpretative analysis of the underlying deeper meaning of the data" (p. 246).

For this study, the approach of Cohen et al. (2007) is used. They suggested four stages of content analysis which are coding, categorizing, comparing and concluding. Dornyei (2007) describes coding as the simplifying the data while keeping the specific features of the text. The categorization process involves assigning labels to a large text in order to make it manageable. The words, phrases, and sentences are grouped into meaningful categories to make connections between and amongst categories. The concluding stage involves inferring results from the content analysis. Concurrent triangulation design suggested by Creswell, Plano Clark, and Gutmann (2003) is used to analyze data. In the concurrent triangulation design model, the data, both quantitative and qualitative, collection and analysis takes place simultaneously and the data integration occurs at the data interpretation stage. Data are interpreted, confirmed, cross-validated and corroborated to establish the findings of the study.

Content analysis as research methodology was adopted for this research because it examines the communicated text for specific purposes considering the social and cultural insights over time, provides insight into human thought and language use while affirming certain words, texts, concepts and themes used focusing the intention of a specific group and detects the disparities in selected content. The guidelines adopted for content analysis were as such: Text was broken down into two major themes IPID and IWoPID.

Content was analyzed for the representation (of) IPID in the communicated text Content was also analyzed for the representation of IPID in pictorial form Content (written text and pictures) was analyzed for the messages given to the audience about IPID.

In this study, the content of textbooks published by public and private publishers were 
analyzed. The public publishers are Punjab Textbook Board, Lahore and Sindh Textbook Board, Jamshoro. The private publishers are Oxford University Press and Gaba Publishers. The researchers read the content, the prose and the poem and examined the pictures. The content was categorized into content by able-bodied for able-bodied; content by ablebodied for IPID; content by IPID for IPID and content by IPID for IWoPID. The analysis also identifies the mention of IPID, who they are, what they do, what they can do and what they cannot do. The images and text also identify how IPID are presented, independent and capable of doing their work with minimum or without any help or dependent on able-bodied.

Table 1

Analysis of English textbooks (Private Publishers)

\begin{tabular}{|c|c|c|c|c|c|}
\hline \multicolumn{6}{|c|}{ GABA Educational Publisher } \\
\hline Class & $\begin{array}{c}\text { Total Images } \\
\text { with human } \\
\text { beings }\end{array}$ & $\begin{array}{l}\text { Images of } \\
\text { IPID }\end{array}$ & $\begin{array}{c}\text { Total } \\
\text { number of } \\
\text { Texts }\end{array}$ & $\begin{array}{c}\text { Texts mentioning } \\
\text { IPID } \\
\text { Positively } \\
\end{array}$ & $\begin{array}{c}\text { Texts mentioning } \\
\text { IPID } \\
\text { negatively }\end{array}$ \\
\hline 1 & 38 & 0 & 19 & 0 & 0 \\
\hline 2 & 44 & 0 & 25 & 0 & 0 \\
\hline 3 & 19 & 0 & 20 & 0 & 0 \\
\hline 4 & 21 & 0 & 21 & 0 & 0 \\
\hline 5 & 20 & 0 & 19 & 0 & 0 \\
\hline \multicolumn{6}{|c|}{ Oxford University Press } \\
\hline 1 & 52 & 0 & 75 & 0 & 0 \\
\hline 2 & 39 & 0 & 21 & 0 & 0 \\
\hline 3 & 35 & 0 & 21 & 0 & 0 \\
\hline 4 & 34 & 0 & 21 & 0 & 0 \\
\hline 5 & 15 & 0 & 20 & 0 & 0 \\
\hline \multicolumn{6}{|c|}{ Afaq Education Publisher } \\
\hline 1 & 88 & 0 & 17 & 0 & 0 \\
\hline 2 & 36 & 0 & 18 & 0 & 0 \\
\hline 3 & 32 & 0 & 18 & 0 & 0 \\
\hline 4 & 52 & 0 & 17 & 0 & 0 \\
\hline 5 & 62 & 0 & 17 & 0 & 0 \\
\hline
\end{tabular}

The analysis of the English language textbooks for primary (class 1 to 5) published by private publishers such as Gaba, Oxford and Afaq shows no evidence of the representation ofIPID either in the text or in pictorial form. Students who will be studying these textbooks will have no idea about IPID. These students will not learn to accept the strengths and talents of IPID, thus considering them as constructive members of the society. The students studying these books will learn to believe that society is composed of people without any physical disabilities hence learning that God has created everyone perfect and none around them is with any sort of weakness or shortcoming. These students may develop an attitude of non- acceptance towards those different from themselves.

The analysis of the English textbooks published by Punjab Textbook Board (PTBB) show representation of IPID in the text and pictorial form only at class 4 level (Table 7, Picture 1). Although the book is composed of 14 chapters there is only one mention of IPID. The text initially mentions a girl who seems to be lonely and sad from the very beginning of the text. She is shown as house-bound and immobile (does not come out of home to play with friends from the neighborhood). Kinza, a girl from the neighborhood 
goes to invite the earlier mentioned girl to join her and other friends in the game.

\begin{tabular}{lccccc} 
Table 2 \\
Analysis of English textbooks (Provincial Publishers) \\
\hline \multicolumn{7}{c}{ Punjab Textbook Board } \\
\hline Class & $\begin{array}{c}\text { Total Images } \\
\text { with human } \\
\text { being }\end{array}$ & $\begin{array}{c}\text { Image } \\
\text { with } \\
\text { IPID }\end{array}$ & $\begin{array}{c}\text { Total } \\
\text { number of } \\
\text { Texts }\end{array}$ & $\begin{array}{c}\text { Texts } \\
\text { mentioning } \\
\text { IPID positively }\end{array}$ & $\begin{array}{c}\text { Texts } \\
\text { mentioning } \\
\text { IPID negatively }\end{array}$ \\
\hline 1 & 21 & 0 & 15 & 0 & 0 \\
2 & 71 & 0 & 25 & 0 & 0 \\
3 & 112 & 0 & 24 & 0 & 0 \\
4 & 20 & 1 & 14 & 1 & 1 \\
5 & 10 & 0 & 11 & 0 & 0 \\
\hline \multicolumn{7}{c}{} & 0 & 0 & 28 & 0 & 0 \\
\hline 1 & 80 & 0 & 8 & 0 & 0 \\
2 & 106 & 0 & 8 & 0 & 0 \\
3 & 85 & 0 & 7 & 0 & 0 \\
4 & 53 & 0 & 5 & 0 & 0 \\
5 & \multicolumn{7}{c}{ Sindh Textbook Board } & 0 \\
\hline
\end{tabular}

To her surprise, Kinza discover that the girl is in a wheelchair and cannot walk. Kinza encourages her to come out and play with the other friends. All the girls in the neighborhood welcome their new friend and modify the game to suit her physical condition instead of playing skipping the rope they decide to play hide and seek. The text gives a lesson that disability should not hinder people from making friends and IWoPID should take initiative in helping and involving IPID in games and other activities (Table 7, Picture 1). The English textbooks of primary classes; 1-5 published by Sindh Textbook Board (STBB) give no evidence of the representation of IPID either in textual or pictorial form thus ignoring and excluding them from mainstream hence assuming them to be non-active and non-productive members of the society.

The Urdu Textbooks published by Gaba and Oxford Publishers show no evidence of IPID. The supposition may be either that society is composed of IWoPID or IPID cannot contribute positively to the progress of the society. On the other hand Urdu books published by Afaq Publishers have representation of IPID at class 1 (Table 7, Picture 2) and 2 level (Table 7, Pictures $3 \& 4$ ). At class 1 the poem is about a good boy and one of the characteristics of this boy is that he is very helpful. In the picture (Table 7) he is shown helping a lame man carry his bag. There is a negative message hidden in this helpfulness. IWoPID are expected to show pity for IPID and help them in simple or complex tasks. The expected behavior of IPID is to depend on others, be reluctant to take any initiative and rely on others in meeting the challenges or routines of life. At class 2 level Afaq Foundation Publishers have represented IPID in 2 different pictures (Table 7, Pictures 3 \& 4) and in one text. The text specifically focuses on the academic achievements of a paralyzed girl. Throughout the text, a positive message is given about IPID stressing their talents and capabilities to progress and achieve heights in life thus making a positive contribution to the lives of those who are attached to them and society at large. The text also teaches one to be helpful rather than sympathetic to IPID. This notion will help society at large to motivate IPID to live with dignity and be useful members of the society. 
Table 3

Analysis of Urdu Textbooks (Private Publishers)

\begin{tabular}{cccccc}
\hline \multicolumn{5}{c}{ GABA Educational Publisher } \\
\hline Class & $\begin{array}{c}\text { Total Images } \\
\text { with human } \\
\text { being }\end{array}$ & $\begin{array}{c}\text { Image } \\
\text { with } \\
\text { IPID }\end{array}$ & $\begin{array}{c}\text { Total } \\
\text { Number } \\
\text { of Texts }\end{array}$ & $\begin{array}{c}\text { Texts } \\
\text { mentioning } \\
\text { IPID positively }\end{array}$ & $\begin{array}{c}\text { Texts } \\
\text { mentioning } \\
\text { IPID negatively }\end{array}$ \\
\hline 1 & 72 & 0 & 47 & 0 & 0 \\
2 & 79 & 0 & 51 & 0 & 0 \\
3 & 50 & 0 & 59 & 0 & 0 \\
4 & 21 & 0 & 34 & 0 & 0 \\
5 & 7 & 0 & 34 & 0 & 0 \\
\hline & \multicolumn{6}{c}{ Oxford University Press } & 0 \\
\hline 1 & 23 & 0 & 17 & 0 & 0 \\
3 & 23 & 0 & 31 & 0 & 0 \\
4 & 14 & 0 & 35 & 0 & 0 \\
5 & 14 & 0 & 42 & 0 & 0 \\
\hline \multicolumn{7}{c}{} & 13 & 0 & 25 & 0 & 0 \\
2 & 61 & 1 & 36 & 0 & 0 \\
3 & 64 & 6 & 35 & 1 & 0 \\
4 & 40 & 0 & 36 & 0 & 0 \\
5 & 24 & 0 & 34 & 0 & 0 \\
\hline
\end{tabular}

At class 2 level, Afaq publishers have given 4 pictures of IPID (Table 7, Pictures 5 \& 6) on a special page highlighting points to be focused on teachers in teaching about IPID.

Table 4

Analysis of Urdu Textbooks (Provincial Publishers)

\begin{tabular}{lccccc}
\hline \multicolumn{6}{c}{ Punjab Textbook Board } \\
\hline $\begin{array}{c}\text { Class } \\
\text { Total Images } \\
\text { with human } \\
\text { being }\end{array}$ & $\begin{array}{c}\text { Images with } \\
\text { with } \\
\text { IPID }\end{array}$ & $\begin{array}{c}\text { Total } \\
\text { number of } \\
\text { Texts }\end{array}$ & $\begin{array}{c}\text { Texts mentioning } \\
\text { IPID } \\
\text { positively }\end{array}$ & $\begin{array}{c}\text { Texts mentioning } \\
\text { IPID } \\
\text { negatively }\end{array}$ \\
\hline 1 & 47 & 0 & 34 & 0 & 0 \\
2 & 91 & 0 & 27 & 0 & 0 \\
3 & 52 & 0 & 27 & 0 & 0 \\
4 & 18 & 1 & 20 & 0 & 1 \\
5 & 20 & 0 & 24 & 0 & 0 \\
\hline \multicolumn{7}{c}{ Sindh Textbook Book Board } \\
\hline 1 & 11 & 0 & 16 & 0 & 0 \\
2 & 15 & 0 & 25 & 0 & 0 \\
3 & 14 & 0 & 25 & 0 & 0 \\
4 & 18 & 0 & 24 & 0 & 0 \\
5 & 10 & 0 & 26 & 0 & 0 \\
\hline
\end{tabular}

A provincial publisher PTBB has mentioned IPID in class 4 (Table 7, Picture 7) in textual and pictorial form. The text mentions in one sentence that IWoPID should be facilitating the blind in their daily routine and the picture highlights a boy helping the blind to cross the road. Though helpfulness is a good attribute teaching reliance on someone may not help others live their lives independently. Should only blind people be helped in crossing the road? Urdu textbooks of primary classes published by STBB do not mention IPID in pictorial form or in the text. IPID are entirely overlooked in the curriculum. This raises a question for the education fraternity: Aren't IPID part of the society? Can't 
IPID contribute in the progress of the society? Do IPID only need the sympathy of others? Shouldn't IPID be independent to live their lives?

Table 5

Analysis of Sindhi (Compulsory) Textbooks (Sindh Text Book Board, Jamshoro)

\begin{tabular}{lccccc}
\hline \multicolumn{5}{c}{ Sindhi (compulsory) Textbooks } \\
\hline Level & $\begin{array}{c}\text { Total Images } \\
\text { with human } \\
\text { beings }\end{array}$ & $\begin{array}{c}\text { Images } \\
\text { with } \\
\text { IPID }\end{array}$ & $\begin{array}{c}\text { Total } \\
\text { number of } \\
\text { Texts }\end{array}$ & $\begin{array}{c}\text { Texts } \\
\text { mentioning } \\
\text { IPID positively }\end{array}$ & $\begin{array}{c}\text { Texts } \\
\text { mentioning } \\
\text { IPID negatively }\end{array}$ \\
\hline 1 & 28 & 2 & 29 & 1 & 0 \\
2 & 61 & 0 & 26 & 0 & 0 \\
3 & 31 & 0 & 28 & 0 & 0 \\
4 & 24 & 0 & 27 & 0 & 0 \\
5 & 26 & 0 & 27 & 0 & 0 \\
\hline
\end{tabular}

Students in the province of Sindh learn three languages: Urdu and English as official languages of communication and Sindhi as the provincial language of communication and in the case of the majority of students as their mother tongue. The analysis of Sindhi (compulsory) textbooks taught at primary schools of Sindh Province reveals that IPID are ignored. However, in the class 1 textbook there is a picture of two disabled people (a blind and a lame man, Table 7, Picture 8). The picture gives the message that both are getting along together. There is only one text about IPID. The text explains the dependability of IPID on each other as the text relates that both the bling and the lame man get into a difficult situation which they could not get out of individually. Inclusivity is ignored in the picture and the text as IPID are shown in isolation talking about their problem and finding a solution for it. Their involvement in the life of society is neither depicted in the story nor highlighted in the picture.

Table 6

Analysis of Asan Sindhi textbooks (Sindh Text Book Board, Jamshoro)

\begin{tabular}{lccccc}
\hline \multicolumn{5}{c}{ Asan Sindhi Textbooks } \\
\hline Class & $\begin{array}{c}\text { Total Images } \\
\text { with human } \\
\text { beings }\end{array}$ & $\begin{array}{c}\text { Images } \\
\text { with } \\
\text { IPID }\end{array}$ & $\begin{array}{c}\text { Total } \\
\text { number of } \\
\text { Texts }\end{array}$ & $\begin{array}{c}\text { Texts } \\
\text { mentioning } \\
\text { IPID positively }\end{array}$ & $\begin{array}{c}\text { Texts } \\
\text { mentioning } \\
\text { IPID negatively }\end{array}$ \\
\hline 3 & 17 & 0 & 26 & 0 & 0 \\
4 & 14 & 1 & 20 & 0 & 1 \\
5 & 13 & 0 & 25 & 0 & 0 \\
\hline
\end{tabular}

In the province of Sindh, Asan (Easy/simple) Sindhi is taught as a compulsory subject in the private English/Urdu medium schools with special reference to the schools of Karachi. The students studying in private schools start learning Sindhi from class 3 level. These books are specially designed for the students whose mother tongue is Urdu, Punjabi, Pushto, Gujrati or English. The analysis of Asan Sindhi Textbooks shows that IPID are mentioned in the text and picture at class 4 level (Table 7, Picture 9). In the picture, a blind man is shown as a beggar and the text relates the story of a beggar. The essence of the story is that blind people are helpless and useless citizens. They are dependent on IWoPID and need their attention and pity. The hidden message is "its OK for them to beg and it's the duty of the citizen to help them financially by giving them 
some money/charity". This lesson teaches students to care for IPID by being sympathetic towards them. IPID are portrayed negatively (beggars) in the picture as well as the text.

\section{Table 7}

Pictures from Textbooks
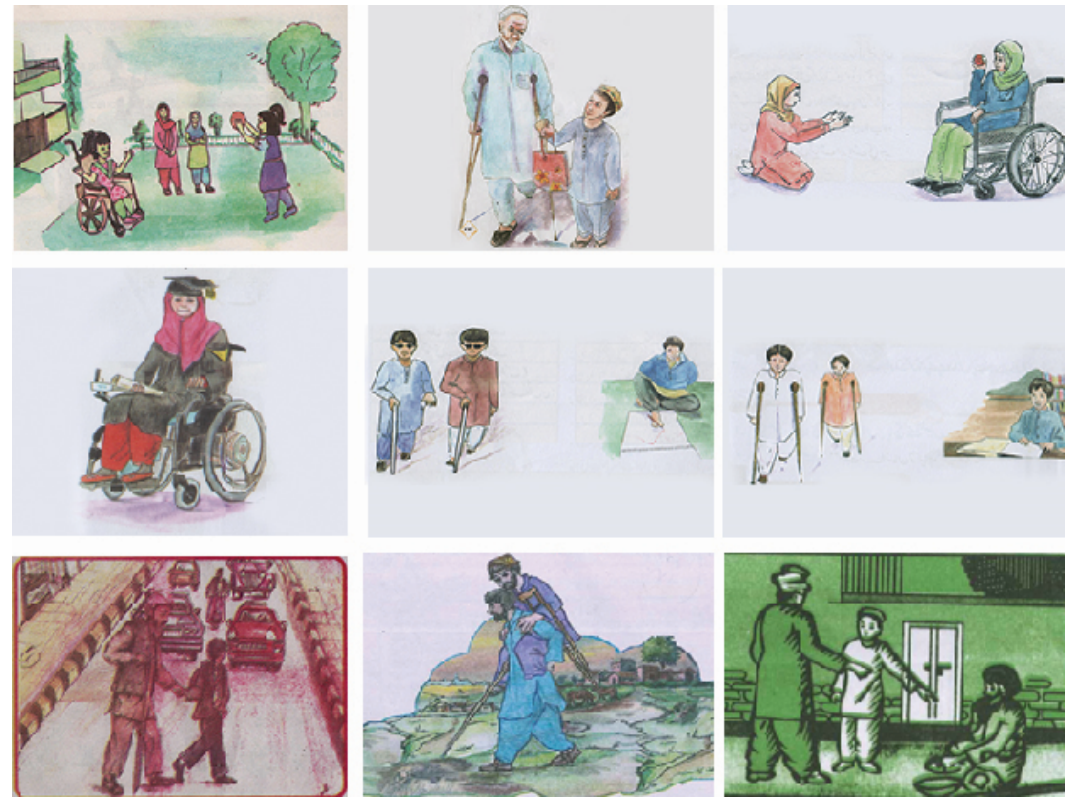

\section{Conclusion}

Society is composed of IPID and IWoPID. Every society is a mixture of these two types of people. In the textbooks analyzed IPID are portrayed as dependable and helpless and only able to survive with the help of others without being actively engaged in everyday activities. Their life is dependent on philanthropic members of the society who give some part of their money to these people. These people are always to be helped financially or physically to survive. In reality, they are seen begging on roads at traffic signals, outside places of worship and in market places. IPID and IWoPID both believe that financial help starting from Rs. 1 and going up to any amount will gain blessings for IWoPID. Therefore blessings from the Almighty are believed to be showered upon those helping IPID. This attitude in the society discourages IPID from earning their living and living a dignified life with self-respect and honor. The portrayal of IPID in negative form teaches IWoPID to have pity on people with special needs thus demoralizing them, disrespecting them, making them feel that they are unable to contribute to the growth and development of the country. A total number of 58 textbooks were analyzed and only 7 textbooks mention IPID with a focus on the blind though Pakistani society is composed of individuals with many types of disabilities such as physical, mental, linguistic and so on. A comprehensive 
curriculum ought to maintain a balance while educating students about the rich contribution IPID make in the growth and development of a society. Furthermore the school curriculum must educate students studying in mainstream schooling that disability is not to be associated with begging but with living a dignified life managing one's day to day activities slightly differently.

Representation of IPID in school curriculum is important to teach students to respect and accept diversity in order to embrace a harmonious style of living with each other. The findings of this study will help textbook publishers in the provinces of Sindh and Punjab to make a policy for the representation of IPID in the textbook and share the related norms with selected writers to ensure that IPID are not ignored or overlooked in the textbook used at primary school level. The study will make a positive impact on students and teachers in understanding that disability is not to be associated with making boundaries, restrictions and limitations, or with being disadvantaged or in need of sympathy. Instead, IPID should be seen as bold in struggling with the challenges of life to live it to the fullest. Therefore textbook writers must give due respect to IPID and ensure their representation in the textbooks while focusing on their positive contribution in building the society. The implication of this study would be that IPID will not be portrayed as 'others' and hence treated differently but considered as dynamic and self-motivated members of the society.

It is recommended that IPID should be portrayed in the school textbooks as active members of the society for making a positive contribution towards its progression. It is also suggested that blindness should not be over emphasized as a disability and neither should blindness be associated with begging. IPID should be portrayed in a way that physical disability should not a barrier to access to education, getting along with children without disability, embracing a profession, earning one's living and participating in regular life activities (though in slightly different ways). Through textbook learning students should be introduced to people having different kinds of disability to appreciate their health as a gift from God and be available to IPID in simple and complex ways to manage the daily routines of life and recognize them as great contributing members of the society thus leading a respectful and dignified life.

Future research could be conducted on topics such as attitude of the public towards IPID, challenges faced by IPID in Pakistani society, facilities available for IPID to manage their daily life activities in schools, hospitals, banks and any other public places and the initiatives taken by the state for the education and literacy of IPID.

Pakistan will make progress only if education (IPID and IWoPID) is taken as a priority by the political, economic and social sectors and by stabilizing governmental structures and strengthening democratic processes (Saad, 2016). This process of progress will be achieved by upgrading the language textbooks (English as official, Urdu as national and Sindhi as Provincial language) portraying the positive role of IPID in the society for its survival. 


\section{References}

Alvermann, D. E., \& Commeyras, M. (1994). Gender, text, and discussion: Expanding the possibilities. Hillsdale, New Jersey, U.S.A: Lawrence Erlbaum Associates Publishers.

Atkinson, P. (1991). The ethnographic imagination: Textual constructions of reality. New York: Routledge, 20(5), 769.

Avramidis, E., \& Norwich, B. (2002). Teachers' attitudes towards integration/inclusion: A review of the literature. European Journal of Special Needs Education, 17(2), 129-147.

Beckett, A. E. (2009). 'Challenging disabling attitudes, building an inclusive society': Considering the role of education in encouraging non-disabled children to develop positive attitudes towards disabled people. British Journal of Sociology of Education, 30(3), 317-329.

Bérubé, M. (1996). Life as we know it: A father, a family, and an exceptional child. New York: Vintage Books.

Berube, M. (1997). The cultural representation of people with disabilities affects us all. The Chronicle of Higher Education B4-B5.

Bickenbach, J. E. (1994). Voluntary disabilities and everyday illnesses. In M. H. Rioux, E M. Bach, disability is not measles: New research paradigms in disability. N. York, Ontario: L Institut Roeher Institute.

Campbell, R., \& Schram, P. J. (1995). Feminist research methods: A content analysis of psychology and social science textbooks. Psychology of Women Quarterly, 19(1), 85-106.

Carspecken, P. F., \& Apple, M. (1992). Critical qualitative research: Theory, methodology, and practice. San Diego CA: Academic Press.

Cheng, K. K., \& Beigi, A. B. (2011). Addressing students with disabilities in school textbooks. Disability \& Society, 26(2), 239-242.

Cohen, L., Manion, L., \& Morrison, K. (2007). Research methods in education. New York: Routledge.

Commeyras, M., \& Alvermann, D. E. (1996). Reading about women in world history textbooks from one feminist perspective. Gender and Education, 8(1), 31-48.

Cook, B. G. (2002). Inclusive attitudes, strengths, and weaknesses of pre-service general educators enrolled in a curriculum infusion teacher preparation program. Teacher Education and Special Education, 25(3), 262-277.

Corbett, J. (1996). Bad-mouthing: The language of special needs. Washington, DC: Falmer Press.

Creswell, J. W., Plano Clark, V. L., \& Gutmann, M. L. (2003). Advanced mixed methods research designs. Thousand Oaks, CA: Sage.

CSIE. (2015). What is inclusion? Retrieved February 10, 2017, from Centre for Studies on Inclusive Education: http://www.csie.org.uk/inclusion/what.shtml.

Diamond, K., \& Tu, H. (2009). Relations between classroom context, physical disability and preschool children's inclusion decisions. Journal of Applied Developmental Psychology, 30(2), 75-81.

Dornyei, Z. (2007). Research methods in applied linguistics: Quantitative, qualitative and mixed methodologies. Oxford, UK: Oxford University Press. 
Douard, J. (1995). Disability and the persistence of the 'normal'. Chronic Illness: From Experience to Policy, 154-175.

Dyches, T. T., Prater, M. A., \& Leininger, M. (2009). Juvenile literature and the portrayal of developmental disabilities. Education and Training in Developmental Disabilities, 44, 304-317.

European Agency for Development in Special Needs Education. (2010). Teacher education for inclusion - International literature review. Odense, Denmark: European Agency for Development in Special Needs Education.

Favazza, P. C., Phillipsen, L., \& Kumar, P. (2000). Measuring and promoting acceptance of young children with disabilities. Exceptional Children, 66(4), 491-508.

Ferguson, P. (2001). On infusing disability studies into the general curriculum. on point... brief discussions of critical issues. Washington, D.C.: Special Education Programs (ED/ OSERS).

Ferguson, P. M., Ferguson, D. L., \& Taylor, S. J. (1992). Interpreting disability: A qualitative reader. New York: Teachers College Press.

Frea, W., Craig-Unkefer, L., Odom, S., \& Johnson, D. (1999). Differential effects of structured social integration and group friendship activities for promoting social interaction with peers. Journal of Early Intervention, 22(3), 230-242.

Harrill, J. L., Leung, J. J., McKeag, R. A., \& Price, J. (1993). Portrayal of handicapped/disabled individuals in children's literature: Before and after public law 94-142. Oshkosh: University of Wisconsin - Oshkosh.

Hodkinson, A. (2016). Constructing impairment and disability in school reading schemes. Education 3-13, 45(5), 572-585.

Hodkinson, A., Ghajarieh, A., \& Salami, A. (2016). An analysis of the cultural representation of disability in school textbooks in Iran and England. Education 3-13, 46(1), 27-36.

Hogan, A., McLellan, L., \& Bauman, A. (2000). Health promotion needs of young people with disabilities-A population study. Disability and Rehabilitation, 22(8), 352-357.

Hogben, M., \& Waterman, C. K. (1997). Are all of your students represented in their textbooks? A content analysis of coverage of diversity issues in introductory psychology textbooks. Teaching of Psychology, 24(2), 95-100.

Home Affairs Division. (1964). Census of Pakistan: Population 1961. Karachi: Ministry of Home and Kashmir Affairs, Government of Pakistan.

Ison, N., McIntyre, S., Rothery, S., Goldsmith, S., Parsonage, S., \& Foy, L. (2010). 'Just like you': A disability awareness programme for children that enhanced knowledge, attitudes and acceptance: Pilot study findings. Developmental Neurorehabilitation, 13(5), 360-368.

Japan International Cooperation Agency. (2002). Country profile on disability: Islamic republic of pakistan. tokyo: Japan international cooperation agency.

Jensen, R., \& Burgess, H. (1997). Mythmaking: How introductory psychology texts present. The Psychological Record, 47(2), 221-232.

Kivirauma, J., \& Laitinen, M. (2014). The changing relationship between disability and education. Arkmedia Oy, Vaasa: The Center for Human Rights of Persons with Disabilities in Finland (VIKE). 
Linton, S. (1998). Claiming disability: Knowledge and identity. New York: University Press.

Llewellyn, A. (2000). Perceptions of mainstreaming: A systems approach. Developmental Medicine and Child Neurology, 42(2), 106-115.

McDougall, J., DeWit, D. J., King, K., \& Miller, L. (2004). High school-aged youths' attitudes toward their peers with disabilities: The role of school and student. International Journal of Disability, Development and Education, 51(3), 287-313.

Mrug, S., \& Wallander, J. L. (2002). Self-concept of young people with physical disabilities: Does integration play a role? International Journal of Disability, Development and Education, 49(3), 267-280.

Neuendorf, K. (2002). The content analysis guidebook. Thousand Oaks: Sage Publications.

Nilholm, C., \& Alm, B. (2010). An inclusive classroom? A case study of inclusiveness, teacher strategies, and children's experiences. European journal of Special Needs Education, 25(3), 239-252.

Office of the High Commissioner for Human Rights. (2010). Monitoring the convention on the rights of persons with disabilities: Guidance for human rights monitors. Geneva: United Nations.

Oliver, M. (1996). Understanding disability: From theory to practice. New York: St Martin's Press.

Pijl, S. J., \& Frostad, P. (2010). Peer acceptance and self-concept of students with disabilities in regular education. European Journal of Special Needs Education, 25(1), 93-105.

Population Census Organization. (1973). Housing, Economic and Demographic Survey 1973. Islamabad: Interior Division.

Population Census Organization. (1984). 1981 Census of Pakistan. Islamabad: Statistics Division.

Rillotta, F., \& Nettelbeck, T. (2007). Effects of an awareness program on attitudes of students without an intellectual disability towards persons with an intellectual disability. Journal of Intellectual and Developmental Disability, 32(1), 19-27.

Saad, I. (2016). Education in Pakistan: Perspective, failures and prospects. Journal of Education E Social Sciences, 4(1), 32-52.

Sándorová, Z. (2014). Content analysis as a research method in investigating the cultural components in foreign language textbooks. Journal of Language and Cultural Education, 2(1), 95-128.

Slininger, D., Sherrill, C., \& Jankowski, C. M. (2000). Children's attitudes toward peers with severe disabilities: Revisiting contact theory. Adapted Physical Activity Quarterly, 17(2), 176-196.

Taxel, J. (1989). Children's literature: A researeh proposal from the perspettive of the soriology of school knowledge. In S. De Castell, A. Luke, \& C. Luke,. Language, Authority and Criticism, 22, 32-45.

Thomson, R. G. (1997). "Integrating disability studies into the existing curriculum: In L. J. Davis the disability studies reader. New York: Routledge.

Thomson, R. G. (2017). Extraordinary bodies: Figuring physical disability in American culture and literature. Columbia University Press.

United Nations. (2013). Accessibility and development: Mainstreaming disability in the post 2015 development agenda. New York: United Nations. 
Waqar, K. (2014). Right to Education Pakistan. Disability: Situation in Pakistan. Lahore, Pakistan.

Weber, R. P. (1990). Basic content analysis. Thousand Oaks: Sage Publications.

Wendell, S. (1997). Toward a feminist theory of disability In L. J. Davis. The Disability Studies Reader, 260-278.

Whitbourne, S. K., \& Hulicka, I. M. (1990). Ageism in undergraduate psychology texts. American Psychologist, 45(10), 1127-1136.

World Health Organization \& World Bank. (2011). World report on disability. Geneva: WHO.

Yu, S., Ostrosky, M. M., \& Fowler, S. A. (2012). Measuring young children's attitudes toward peers with disabilities: Highlights from the research. Topics in Early Childhood Special Education, 32(3), 132-142.

Zaidi, B., \& Zaki, S. (2017). English language in Pakistan: Expansion and resulting implications. Journal of Education \& Social Sciences, 5(1), 52-67.

Zevallos, Z. (2011). What is Otherness? Retrieved March 5, 2017, from The Other Sociologist: https://othersociologist.com/otherness-resources/. 